\title{
Fermented Inonotus Obliquus Inhabit Proliferation of Hepatocellular Carcinoma HepG2 Cells through inducing Apoptosis and G0/G1 Cell Cycle Arrest
}

\author{
Rui Hou ${ }^{1}$ and Weiping $\mathrm{Ma}^{2 *}$ \\ ${ }^{1}$ Department of Ultrasonic Diagnosis, China \\ ${ }^{2}$ School of Medicine and pharmacology, China
}

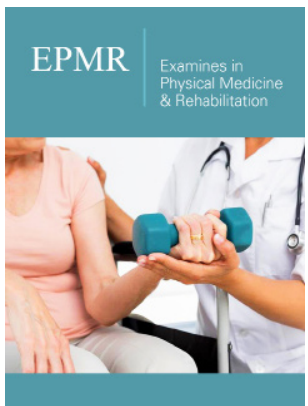

For HTML Version scan this QR code:

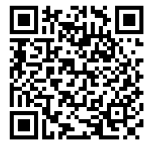

*Corresponding author: Weiping Ma, School of Medicine and Pharmacology, China

Submission: 洒 January 21, 2019

Published: 阱 March 11, 2019

Volume 2 - Issue 3

How to cite this article: Rui H, Weiping M. Fermented Inonotus Obliquus Inhabit Proliferation of Hepatocellular Carcinoma HepG2 Cells through inducing Apoptosis and G0/G1 Cell Cycle Arrest. COJ Nurse Healthcare.2(3). EPMR.000536.2019. DOI: 10.31031/EPMR.2019.02.000536.

Copyright@ Weiping Ma, This article is distributed under the terms of the Creative Commons Attribution 4.0 International License, which permits unrestricted use and redistribution provided that the original author and source are credited.

\begin{abstract}
Inonotus obliquus have many pharmacological effects. The aim of this study was to evaluate the effect of fermented Inonotus obliquus (FIO) on hepatocellular carcinoma HepG-2 cells and preliminarily study on possible mechanism. The contents of polysaccharides, terpenoids and polyphenols in unfermented Inonotus Obliquus (UIO) and FIO were determined and he effect of on hepatocellular carcinoma HepG-2 cells was determined. Compared with UIO, the contents of polysaccharides, polyphenols and terpenoids of FIO were significantly increased $(\mathrm{P}<0.01)$. FIO significantly inhibited the proliferation of HepG-2 cells and induced HepG-2 apoptosis. The mechanism may be through increased the ratio of G0/G1 phase was $(\mathrm{P}<0.05)$ and increase the expression of Cytochrome $\mathrm{C}$ and Caspase- 3 apoptotic proteins.
\end{abstract}

Keywords: Fermented inonotus obliquus; Apoptosis; Cell cycle arrest

\section{Introduction}

Hepatocellular carcinoma has been the fourth highest incidence of cancer and the annual incidence of hepatocellular carcinoma is about 26/10 million in China [1]. Inonotus obliquus (Fr.) Pilat belongs to Basidiomycetes, Paracoccus and Pleurotus. Wild Inonotus obliquus is mainly grown in latitude $40^{\circ}-50^{\circ}$. Earlier, Inonotus obliquus have been used to treat gastrointestinal cancer, cardiovascular disease and diabetes [2]. Some parts of the world are still using Inonotus obliquus and its extract to treat related diseases. The main pharmacological effects of Inonotus obliquus include anti-cancer, anti-oxidation, immune-regulatory effects, anti-inflammatory, anti-bacterial, fungal [3]. The pharmacological effects and mechanism of the wild Inonotus obliquus was investigated, but there is no report on the apoptosis of fermented Inonotus obliquus on HepG-2 cells. In this study, MTT assay, flow cytometry and agarose gel electrophoresis were used to investigate the effect of Inoculation on the apoptosis of HepG-2 cells.

\section{Materials \& Methods}

\section{Changes of antitumor composition of Inonotus obliquus}

Polysaccharide content of fermented Inonotus obliquus was determined by Sulfuric acidphenol method [4]. Polysaccharides of the sample solution were extracted, and glucose as the standard, draw the standard curve. The content of polysaccharide of unfermented and fermented Inonotus obliquus was determined. Triterpenoids content of the Fermented Inonotus obliquus was determined by UV spectrophotometry [5]. After extracting of the total triterpenoid compounds, the standard curve was drawn with betulin as the standard. The content of triterpenoids of unfermented and fermented Inonotus obliquus was determined by folium-Ciocalteu Method. Polyphenol content of the fermented Inonotus obliquus was determined by Folin-Ciocalteu method [6]. After extracting of polyphenols, $d$ the standard curve was drawn with gallic acid as a standard. The contents of polyphenols of unfermented and fermented were determined. 


\section{Cell viability analysis}

Cell viability was assessed by MTT $\{3-(4,5$-dimethylthiazol-2yl)-2, 5-diphenyl tetrazolium bromide) $\}$ assay. Briefly, the cells were placed in 96-well culture dishes (Nunclon, Roskilde, Denmark) at a density of $5 \times 10^{4}$ cells/well in DMEM culture medium that contained $10 \%$ FBS and then incubated at $37{ }^{\circ} \mathrm{C}$ under $5 \% \mathrm{CO}_{2}$. After $24 \mathrm{~h}$, the cells were washed and placed in culture medium with different concentrations of UIO and FIO (100, 200,400 and $800 \mathrm{mg} / \mathrm{L}$ ) for $48 \mathrm{~h}$. Next, $20 \mathrm{~mL}$ of MTT solution (5mg MTT/mL in PBS) was added to each well of a microtiter plate and the samples were then incubated for $4 \mathrm{~h}$ at $37^{\circ} \mathrm{C}$. After washing, the formazan dye precipitates, which are proportional to the number of live cells, were dissolved in $100 \mathrm{~mL}$ of DMSO. The absorbance at $540 \mathrm{~nm}$ was then read using a microtiter plate reader (Thermo Electron, Vantaa, Finland). The rate of cell growth inhibition was calculated using the following formula: mean value of $\{$ (control group - treated group)/ control group $\times 100 \%$. The effects of each concentration were analysed in triplicate.

\section{Annexin V-FITC/propidium iodide flow cytometric analysis staining}

HepG-2 cells were plated at a density of $5 \times 10^{6}$ per $10 \mathrm{~cm}^{2}$ dish and cultured with different concentrations of UIO and FIO (100,200 and $400 \mathrm{mg} / \mathrm{L}$ ) for $48 \mathrm{~h}$. A total of $1 \times 10^{6}$ cells was washed in icecold PBS and resuspended in $1 \times$ binding buffer at a concentration of $1 \times 10^{6}$ cells $/ \mathrm{mL}$. One-hundred $\mu \mathrm{L}$ of the solution was transferred into a 5 -mL culture tube. Then, $5 \mu \mathrm{L}$ of FITC Annexin V(25 $\mu \mathrm{g} / \mathrm{mL})$ and $5 \mu \mathrm{L}$ of propidium iodide $(250 \mu \mathrm{g} / \mathrm{mL})$ were added. Cells were gently vortexed and incubated at room temperature $\left(25^{\circ} \mathrm{C}\right)$ in the dark for $10 \mathrm{~min}$. Finally, $490 \mu \mathrm{L}$ of $1 \times$ binding buffer to each tube were added and analyzed by flow cytometry within $1 \mathrm{~h}$.

\section{Analysis of cell cycle by flow cytometer}

After treatment with various concentrations of UIO and FIO $(100,200$ and $400 \mathrm{mg} / \mathrm{L})$ for $48 \mathrm{~h}, \mathrm{HepG}-2$ cells were harvested and washed with cold PBS twice, then adjusted to a concentration of $1 \times 10^{6}$ cells $/ \mathrm{ml}$. Cell cycle progression was determined by flow cytometry analysis with a propidium iodide (PI) staining cell cycle assay kit. Staining was performed according to the manufacturer's instructions. Fluorescent signals were detected through the FL2 channel and the proportion of DNA in different phases was analyzed using ModfitLT Version 3.0 (Verity Software House, Topsham ME. USA).

\section{DNA gel electrophoresis analysis}

After treatment with various concentrations of UIO and FIO $(100,200$ and $400 \mathrm{mg} / \mathrm{L})$ for $48 \mathrm{~h}, \mathrm{HepG}-2$ cells were harvested and washed with cold PBS twice, centrifuged. The cell DNA fragments were extracted according to the kit requirements and gel electrophoresis.

\section{Western bolttiong}

For Western blotting assay, cells were treated with the indicated drugs, and protein from whole cell lysates were prepared and detected as previously described.

\section{Statistical analysis}

An analysis of variance (ANOVA) was completed. The mean comparison was carried out by Duncan's Multiple Range Tests (DMRT). The significance of difference was defined at $\mathrm{p}<0.05$. The analysis was performed by using an SPSS package (SPSS 17.0 for window, SPSS Inc, Chicago, IL).

\section{Results}

\section{Changes of antitumor composition of Inonotus obliquus}

Changes of polysaccharide content in Inonotus Obliquus. The polysaccharide content in UIO and FIO is $7.161 \pm 0.305 \mathrm{mg} / \mathrm{mL}$, $10.14 \pm 0.849 \mathrm{mg} / \mathrm{mL}$ determined by sulfuric acid-phenol method, respectively. Compare with in UIO, the polysaccharide content in FIO remarkably increased $(\mathrm{P}<0.01)$. Changes of triterpenoids content in Inonotus Obliquus. The triterpenoids content in UIO and FIO determined by Folium-Ciocalteu Method is $1.358 \pm 0.004 \mathrm{mg} /$ $\mathrm{mL}, 1.774 \pm 0.001 \mathrm{mg} / \mathrm{mL}$, respectively. Compare with in UIO, the triterpenoids content in FIO observably increased $(\mathrm{P}<0.01)$. Changes of polyphenol content in Inonotus Obliquus. The polyphenol content in UIO and FIO is $6.314 \pm 0.237 \mathrm{mg} / \mathrm{mL}, 9.979 \pm 0.022 \mathrm{mg} / \mathrm{mL}$, respectively. And compare with in UIO, the polyphenol content in FIO observably increased $(\mathrm{P}<0.01)$ (Figure 1$)$. UIO and FIO were dried and subjected to the following experiments.

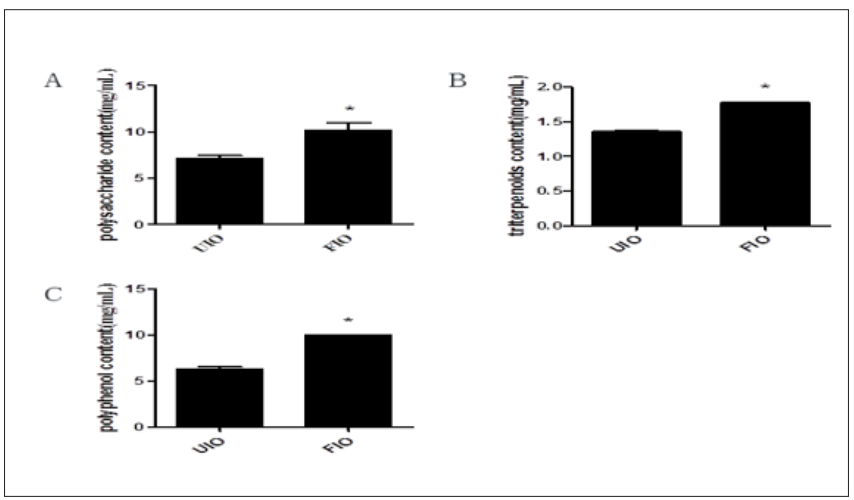

Figure 1: Effect of fermentation on composition content, A) polysaccharide content, B) triterpenoid content, C) polyphenol content. All data are expressed as the mean $\pm \mathrm{SE}$. ${ }^{*} \mathrm{P}<0.05$, vs UIO. 


\section{Cell viability analysis}

To evaluate the effects of FIO on the growth and survival of HepG-2 cells, the cells were exposed to various concentrations (100$800 \mathrm{mg} / \mathrm{L}$ ) of FIO for $48 \mathrm{~h}$ and their viability was then evaluated by an MTT assay. Treatment with FIO led to decreases in cell viability in a dose-dependent manner. Furthermore, the decrease induced by FIO was significantly greater than the decrease induced by UIO. Therefore, further experiments were conducted using $100 \mathrm{mg} / \mathrm{L}$, treat time for $48 \mathrm{~h}$, because of inhibitive rate close to IC50(Figure 2).

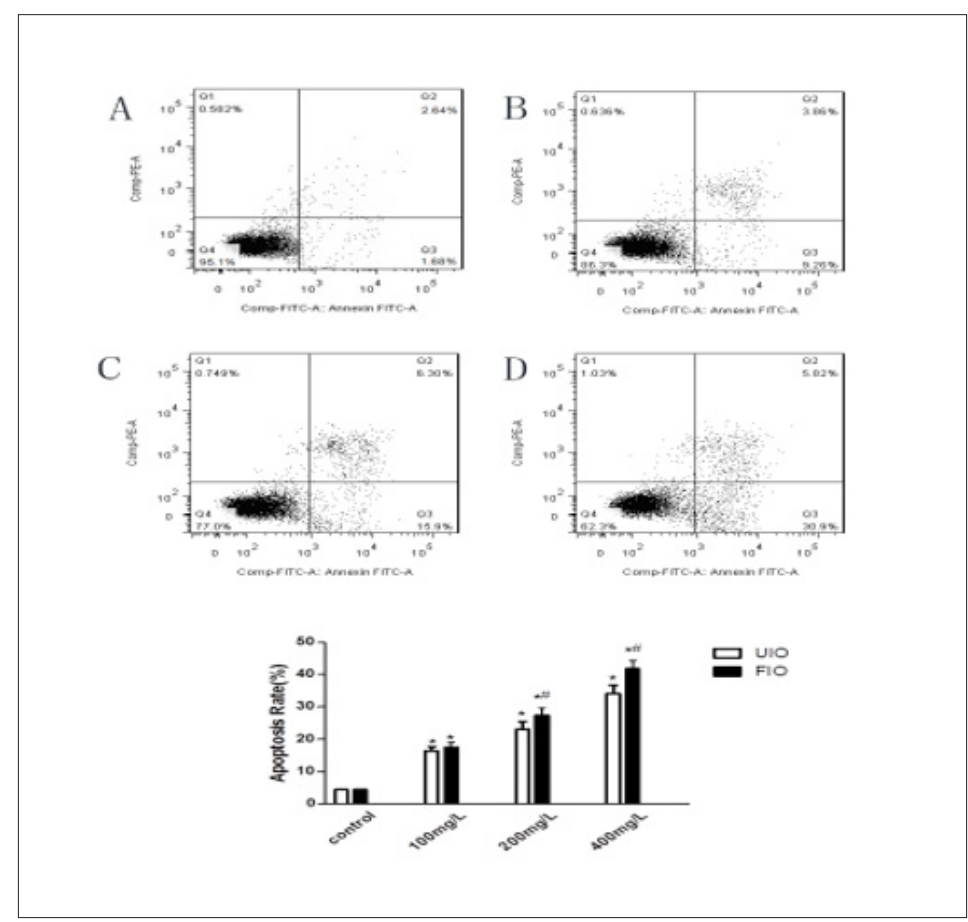

Figure 2: The inhibitory effects of FIO on the proliferation of HepG-2 cells. The HepG-2 cells were treated with UIO and FIO $(100,200,400$ and $800 \mathrm{mg} / 1)$ for $48 \mathrm{~h}$. UIO. All data are presented as mean value \pm SD and $\mathrm{n}=6 \mathrm{in}$ each group. ${ }^{*} \mathrm{P}<0.05$, vs UIO

\section{Apoptosis induced by FIO in HepG-2 cells}

Morphological changes were visualized by using DAPI nuclear staining under a fluorescence microscope after treatment with different concentrations $(100 \mathrm{mg} / \mathrm{L}, 200 \mathrm{mg} / \mathrm{L}$ and $400 \mathrm{mg} / \mathrm{L})$ of FIO. Treatment with FIO led to a decreasing the number of HepG-2 cells, as well as an increasing degree of apoptosis with some obvious apoptotic morphological alterations such as improved brightness, chromatin pyknosis and fragmentation. Furthermore, apoptosis (including LR, the early apoptotic cells and UR, late apoptotic cells) was measured with Annexin V-FITC/PI double-labelled flow cytometry. The percent of HepG-2 cells undergoing apoptosis following treatment with 100,200 and $400 \mathrm{mg} / \mathrm{L}$ of FIO for $48 \mathrm{~h}$ was $17.44 \%, 27.37 \%$ and $41.80 \%$, respectively. For UIO, the apoptosis rate was $16.4 \%, 23.14 \%$ and $34.16 \%$, respectively. Compared with UIO, Apoptosis induced by FIO remarkably increased $(\mathrm{P}<0.01)$ (Figure 3).

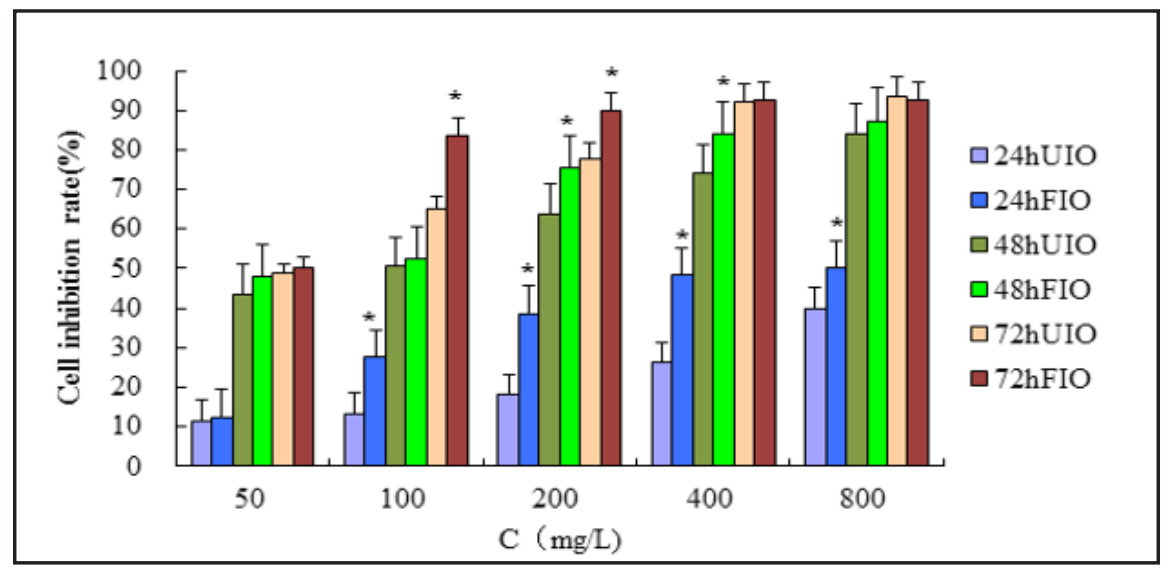

Figure 3: Effect of FIO on Apoptosis Rate of HepG-2 Cells. The HepG-2 cells were treated with blank DMEM medium (A) Control, (B)FIO 100mg/L, (C)FIO 200mg/L and(D) FIO 400mg/L for 48h UIO. All data are presented as mean value $\pm \mathrm{SD}$ and $\mathrm{n}=3$ in each group. ${ }^{*} \mathrm{P}<0.01$, vs Control; $\# \mathrm{P}<0.01$, vs UIO. 


\section{Cell cycle arrest activities}

Flow cytometer analysis was further performed to detect the cell cycle arrest activity of FIO in HepG-2 cells. The percentage proportion of $\mathrm{S}$ phase cells was reduced significantly after exposure to 100,200 and $800 \mathrm{mg} / \mathrm{L}$ of FIO (45.93,48.20 and 41.38
$\%$, respectively) when compared with that of the control cells (51.57\%), suggesting that FIO inhibited HepG-2 cells proliferation by blocking the cell cycle at $\mathrm{G} 1$ to $\mathrm{S}$ progression $(\mathrm{P}<0.01)$. Compared with UIO, percentage proportion of $\mathrm{S}$ phase cells of FIO was reduced significantly $(\mathrm{P}<0.05)$ (Figure 4 \& Table 1$)$.

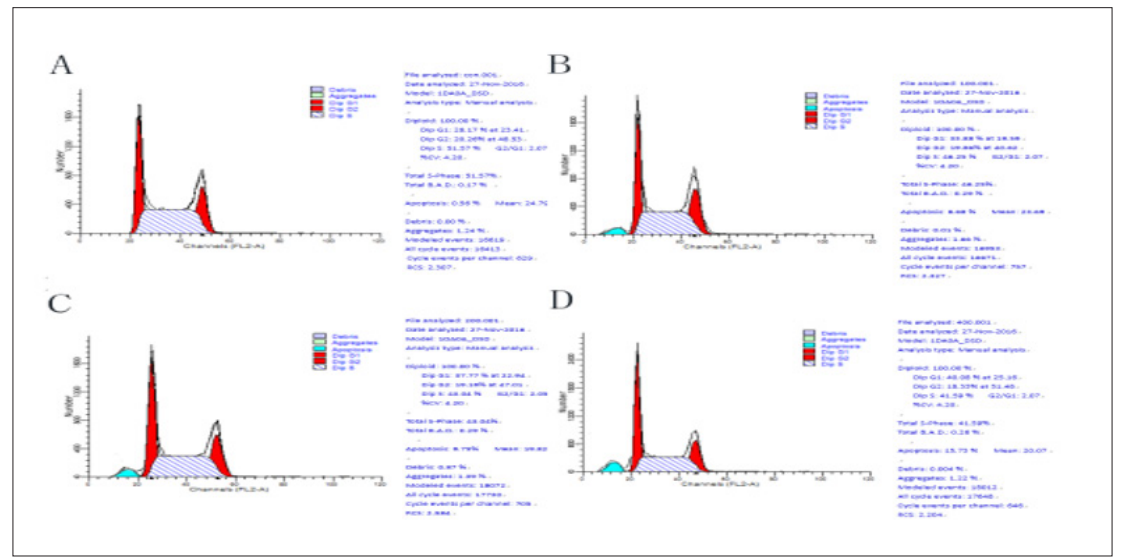

Figure 4: Effect of FIO on cell cycle of HepG2 cells. The HepG-2 cells were treated with blank DMEM medium (A) Control, (B) FIO 100mg/L, (C) FIO 200mg/L and (D) FIO 400mg/L for 48h.

Table 1: Effect of FIO on cell cycle of HepG-2 cells.

\begin{tabular}{|c|c|c|c|c|c|c|c|c|c|c|c|c|}
\hline \multirow[t]{2}{*}{ Group } & \multicolumn{3}{|c|}{ Control } & \multicolumn{3}{|c|}{$100 \%$} & \multicolumn{3}{|c|}{$200 \%$} & \multicolumn{3}{|c|}{$400 \%$} \\
\hline & $\begin{array}{c}\text { G0/G1 } \\
(\%)\end{array}$ & S (\%) & $\begin{array}{c}\text { G2/M } \\
(\%)\end{array}$ & G0/G1 1 (\%) & S (\%) & $\begin{array}{c}\text { G2/M } \\
(\%)\end{array}$ & $\begin{array}{c}\text { G0/G1 } 1 \\
(\%)\end{array}$ & S (\%) & $\begin{array}{c}\text { G2/M } \\
(\%)\end{array}$ & $\begin{array}{c}\text { G0/G1 } 1 \\
(\%)\end{array}$ & $\mathrm{S}(\%)$ & G2/M (\%) \\
\hline \multirow[t]{2}{*}{ UIO } & 28.17 & 51.5 & 20.26 & 34.4 & $45.93^{*}$ & $19.64^{*}$ & $30.02^{*}$ & 48.2 & $21.78^{*}$ & $40.29^{*}$ & 41.3 & $18.33^{*}$ \\
\hline & & 7 & & $3^{*}$ & & & & $0^{*}$ & & & $8^{*}$ & \\
\hline \multirow[t]{3}{*}{ FIO } & 28.17 & 51.5 & 20.26 & 33.8 & $46.25^{*}$ & $19.86^{*}$ & $37.77^{*}$ & 43 & & & & \\
\hline & & 7 & & $8^{*}$ & & & $\#$ & $4^{*}$ & $19.19^{*}$ & $40.08^{*}$ & 41.5 & $18.33^{*}$ \\
\hline & & & & & & & & $\#$ & $\#$ & & $9^{*}$ & \\
\hline
\end{tabular}

Notes: Values are expressed as mean $\pm \mathrm{SD}$ in each group. In each column, same letters indicate no significant difference $(\mathrm{P}>0.05)$, with significant difference $(\mathrm{P}<0.05)$.

\section{DNA gel electrophoresis analysis}

Compared with UIO, the DNA fragments of FIO groups were significantly higher than those in the untreated group (Figure 5). The DNA fragments of UIO and FIO were not significantly different from those of UIO.

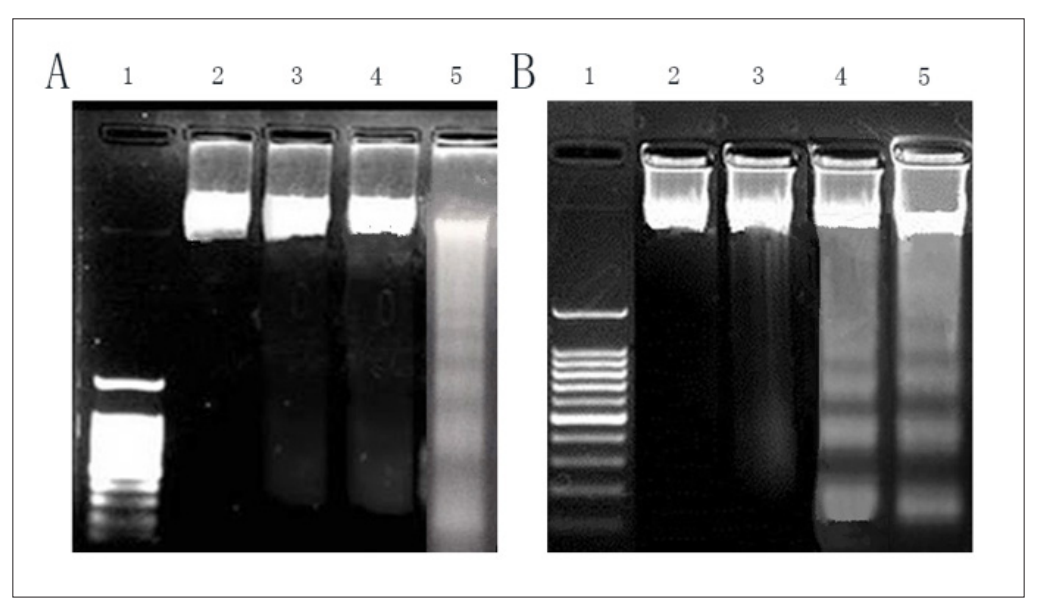

Figure 5: Effect of FIO on DNA of HepG2 cells. The HepG-2 cells were treated with blank DMEM medium (2); FIO $100 \mathrm{mg} / \mathrm{L}$ (3) FIO 200mg/L (4) and FIO 400mg/L (5) for48h. A treated with UIO; B treated with FIO. 


\section{Western blotting}

Compared with the control group, the expression of Caspase-3 and cyt-c protein ware significantly increased $(\mathrm{P}<0.01)$, and the protein expression increased significantly with the increase of drug concentration, and Compared with UIO group, the expression of Caspse-3 and cyt-c in the fermented Inonotus obliquus was not significant (Figure 6).

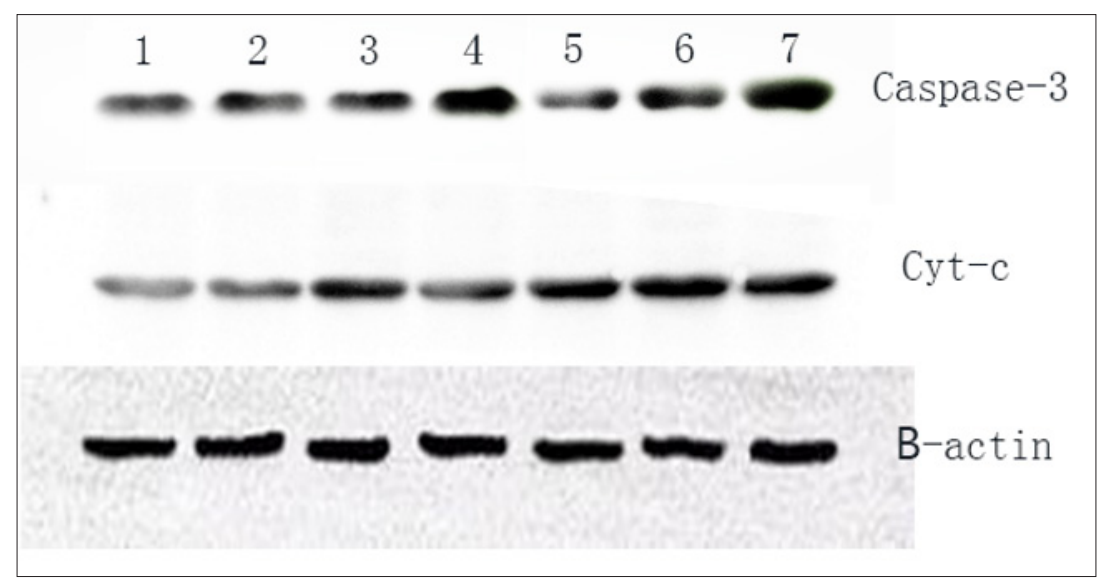

Figure 6: The expression of Caspase-3 and cyt-c protein. The HepG-2 cells were treated with blank DMEM medium (1); UIO 100mg/L (2) UIO 200mg/L (3) and UIO 400mg/L (4); FIO 100mg/L (5) FIO 200mg/L (6) and FIO 400mg/L (7) for48h. A treated with UIO; B treated with FIO.

\section{Discussion}

Studies have reported that Inonotus obliquus can significantly inhibit tumour growth with the inoculated harsh conditions of Inonotus obliquus and limited resources of wild Inonotus obliquus. The main anti-tumour substances of Inonotus obliquus include polysaccharides, polyphenols and terpenoids. Liu X found that compared with the control group, polysaccharide and polyphenol content of Inonotus obliquus deep fermentation were significantly increased. The content of triterpenoids was also significantly increased in Inonotus obliquus deep fermentation [7]. In this study, the content of polysaccharides, terpenoids and polyphenols in unfermented and fermented Inonotus obliquus was determined, respectively. The contents of polysaccharides, polyphenols and terpenoids were increased, compared with wild Inonotus obliquus. Fermentation has the advantages of short production cycle and high active ingredient content. In this study, we investigated the effect of the fermented Inonotus obliquus on the apoptosis of HepG-2 cells. Chen [8] Found that extracts of Inonotus obliquus can significantly inhibit the proliferation of hepatocellular carcinoma cells HePG2 and SMMC7721 cells [8]. In this study, it was found that the fermented Inonotus obliquus had a significant inhibitory effect on HepG-2 cells, and the inhibitory effect increased with the increase of concentration and the prolongation of the time. The inhibition rate of hepatocellular carcinoma HepG-2 cells was $52.36 \%$ at $48 \mathrm{~h}$, and the inhibitory concentration (IC50) was close to that of HepG-2 cells. And the inhibitory effect on the growth of hepatocellular carcinoma cells of fermented Inonotus obliquus was more significant than that of the unfermented Inonotus obliquus $(\mathrm{P}<0.05)$. Therefore, the concentration of $100 \mathrm{mg} / \mathrm{L}, 48 \mathrm{~h}$ was chosen to experience.

The result of Annexin-V/PI double staining showed that the apoptosis of HepG2 cells could induce the apoptosis of HepG2 cells, and the apoptotic effect and the concentration of Annexin-V/
PI were lazy. Compared with unfermented Inonotus obliquus, the fermentation of Inonotus obliquus has a higher induction of apoptosis. Youn et al. [9] found that Inonotus obliquus induced apoptosis by G0/G1 arrest in HepG2 cells [9]. In this study, it was found that the apoptosis rate of HepG-2 cells was significantly higher than that of the control group, and it was positively correlated with the dose. At the same time, the distribution of G0/G1 phase cells increased significantly, and the S and G2/M periods were significantly decreased compared with the control group, suggesting that the fermented Inonotus obliquus induce the apoptosis of hepatocellular carcinoma HepG2 cells by G0/G1 phase arrest. In addition, compared with the unferricidal Inonotus obliquus group, the G0/G1 phase cell block was more significantly induced when the concentration of Inoculum was $200 \mathrm{mg} / \mathrm{L}$.

In summary, this study found that the fermented Inonotus obliquus has significant inhibition of proliferation and induction of apoptosis on HepG-2 cells with the dose and duration of time and could significantly affect the cell cycle distribution and make the cell cycle arrested in G0/G1 phase and induced apoptosis of hepatocarcinoma cells. The results of this study show that the fermented Inonotus obliquus may have better pro-apoptotic effect than that of unfermented Inonotus obliquus, and its mechanism should be further studied.

At the early stage of apoptosis, the activated Caspase- 3 protein cleaves the substrate by cleavage of the corresponding cytoplasmic nucleus. The most important substrate for Caspase-3 is polyadenosine diphosphate ribose polymerase, which is involved in promoting DNA repair and maintaining the integrity of the gene. When the cell is apoptotic, polyadenyl adenine diphosphate ribose polymerase is cleaved by Caspase-3, so that the enzyme cannot play the role of DNA repair and maintain complete DNA, the activity of endonuclease in cells is enhanced, and the gene cleavage, Induced apoptosis. Nomura et al. [10] also found that bergenotrophic acid 
can inhibit tumor cell proliferation by acting on Caspase-3 genes associated with apoptosis [10]. In this experiment, the expression of Caspase-3 protein was significantly increased in the untreated and fermented Isoe camourei group compared with the control group by western blot. The expression of Caspase- 3 protein was also increased with the increase of dose. There was no significant difference in the expression of Caspase-3 protein between the two groups. Suggesting that the fermentation of Inonotus obliquus may be caused by upregulation of Caspase-3 protein expression in human hepatocellular carcinoma HepG2 cells.

\section{Conclusion}

The present study demonstrates the apoptosis of HepG-2 cells was induced by fermented Inonotus obliquus, and the apoptosis of hepato-carcinoma HepG-2 cells was more significant than that of unfermented Inonotus obliquus.

\section{References}

1. Zheng RJ, Fu Y, Xiang QF, Yang M, Chen L, et al. (2016) Knowledge, attitudes, and influencing factors of cancer patients toward approving advance directives in China. Support Care Cancer 24(10): 4097-4103.

2. Lin SY, Yeh CC, Liang CH, Mau JL (2012) Preparation of Chaga medicinal mushroom, Inonotus obliquus-fermented rice using solid-state fermentation and its taste quality and antioxidant property. Int J Med Mushrooms 14(6): 581-592.

3. Lemieszek MK, Langner E, Kaczor J, Kandefer SM, Sanecka B, et al (2015) Anticancer effects of fraction isolated from fruiting bodies of Chaga medicinal mushroom, Inonotus obliquus (Pers.: Fr.) Pilát (Aphyllophoromycetideae): in vitro studies. Int J Med Mushrooms 13: 131-43.

4. Guo XF, Piao ZY, Wang SM (2015) Comparative analysis of different Inonotus obliquus. Zhong Yao Cai 38: 669-673.

5. Xu X, Xu Z, Shi S, Lin M (2017) Lignocellulose degradation patterns, structural changes, and enzyme secretion by Inonotus obliquus on straw biomass under submerged fermentation. Bioresour Technol 241: 415423.

6. Boratyński J, Zal T (1990) Colorimetric micro methods for glutaraldehyde determination by means of phenol and sulfuric acid or phenol and perchloric acid. Anal Biochem 184(2): 259-262.

7. Liu X, Zhu L, Tan J, Zhou X, Xiao L, et al. (2014) Glucosidase inhibitory activity and antioxidant activity of flavonoid compound and triterpenoid compound from Agrimonia Pilosa Ledeb. BMC Complement Altern Med 14: 12 .

8. Chen Y, Gu X, Huang SQ, Li J, Wang X, et al. (2010) Optimization of ultrasonic/microwave assisted extraction (UMAE) of polysaccharides from Inonotus obliquus and evaluation of its anti-tumor activities. Int J Biol Macromol 46(4): 429-435.

9. Youn MJ, Kim JK, Park SY, Kim Y, Kim SJ, et al. (2008) Chaga mushroom (Inonotus obliquus) induces G0/G1 arrest and apoptosis in human hepatoma HepG2 cells. World J Gastroenterol 14(4): 511-517.

10. Nomura M, Takahashi T, Uesugi A, Tanaka R, Kobayashi S (2008) Inotodiol, a lanostane triterpenoid, from Inonotus obliquus inhibits cell proliferation through caspase-3-dependent apoptosis. Anticancer Res 28(5A): 2691-2696 